\title{
Resolution, structures and vibrational circular dichroism of helicoidal trinickel and tricobalt paddlewheel complexes
}

\author{
Miguel Cortijo, ${ }^{[a, b]}$ Ángela Valentín-Pérez, ${ }^{[a, b]}$ Patrick Rosa, ${ }^{[a]}$ Nicolas Daugey, ${ }^{[c]}$ Thierry \\ Buffeteau, ${ }^{*[c]}$ Elizabeth A. Hillard*[b]
}

\author{
[a] Dr. Á. Valentín-Pérez, Dr. M. Cortijo, Dr. P. Rosa \\ CNRS, University of Bordeaux, ICMCB UMR 5026, 87, Avenue Schweitzer, 33600 Pessac, France \\ [b] Dr. Á. Valentín-Pérez, Dr. M. Cortijo, Dr. E. A. Hillard \\ CNRS, University of Bordeaux, CRPP UMR 5031, 115, Avenue Schweitzer, 33600 Pessac, France \\ e-mail: elizabeth.hillard@crpp.cnrs.fr \\ [c] Dr. T. Buffeteau, Dr. N. Daugey \\ CNRS, University of Bordeaux, ISM, UMR 5255, 351 Cours de la Libération, 33405 Talence, France \\ e-mail: thierry.buffeteau@u-bordeaux.fr
}

\begin{abstract}
It has been recently shown that enantiomers of the helicoidal paddlewheel complex $\left[\mathrm{Co}_{3}(\mathrm{dpa})_{4}\left(\mathrm{CH}_{3} \mathrm{CN}\right)_{2}\right]^{2+}(\mathrm{dpa}=$ the anion of 2,2'-dipyridylamine) can be resolved using the chiral $\left[\mathrm{As}_{2}(\text { tartrate })_{2}\right]^{2-}$ anion $(\mathrm{AsT})$, and that these complexes demonstrate a strong chiroptical response in the UV-visible and X-ray energy regions. Here we report that the nickel congener, $\left[\mathrm{Ni}_{3}\left(\mathrm{dpa}_{4}\left(\mathrm{CH}_{3} \mathrm{CN}\right)_{2}\right]^{2+}, \mathrm{can}\right.$ likewise be resolved using AsT. Depending on the stereochemistry of the enantiopure AsT anion, one or the other of the trinickel enantiomers crystallize from $\mathrm{CH}_{3} \mathrm{CN}$ and diethyl ether in space group $P 42_{1} 2$ as the $\left(\mathrm{NBu}_{4}\right)_{2}\left[\mathrm{Ni}_{3}(\mathrm{dpa})_{4}\left(\mathrm{CH}_{3} \mathrm{CN}\right)_{2}\right](\text { AsT })_{2} \cdot$ : $[$ solvent] salt. After resolution, the AsT salts were converted into the $\mathrm{PF}_{6}{ }^{-}$salts by anion exchange, with retention of the chirality of the trinickel complex. The enantiopure $\left[\mathrm{Ni}_{3}(\mathrm{dpa})_{4}\left(\mathrm{CH}_{3} \mathrm{CN}\right)_{2}\right]\left(\mathrm{PF}_{6}\right)_{2} \cdot 2 \mathrm{CH}_{3} \mathrm{CN}$ and $\left[\mathrm{Co}_{3}(\mathrm{dpa})_{4}\left(\mathrm{CH}_{3} \mathrm{CN}\right)_{2}\right]\left(\mathrm{PF}_{6}\right)_{2} \cdot \mathrm{CH}_{3} \mathrm{CN} \cdot \mathrm{C}_{4} \mathrm{H}_{10} \mathrm{O}$ compounds crystallize in space groups $C 2$ and $P 2_{1}$, respectively. Both the $\mathrm{Ni}(\mathrm{II})$ and $\mathrm{Co}$ (II) complex cations are stable towards racemization in $\mathrm{CH}_{3} \mathrm{CN}$. Vibrational circular dichroism (VCD) data obtained in $\mathrm{CD}_{3} \mathrm{CN}$ demonstrate the expected mirror image spectra for the enantiomers, the observed peaks arising from the dpa ligand. The VCD response is significant, with $\Delta \varepsilon$ values up to $6 \mathrm{Lmol}^{-1} \mathrm{~cm}^{-1}$ and vibrational dissymmetry factors on the order of $10^{-3}$. DFT calculations well reproduce the experimental spectra, showing little difference between the peak position, sign, and intensity in the VCD for the cobalt and nickel complexes. These results suggest that VCD enhancement of these peaks is unlikely, and their remarkable intensity may be due to their rigid helicoidal structure.
\end{abstract}

Keywords: paddlewheel complexes, helicoidal chirality, arsenyl tartrate, chiral resolution, X-ray crystallography, vibrational circular dichroism

\section{Introduction}

Polynuclear paddlewheel complexes, also called "Extended Metal Atom Chains", or "Metal Strings", consist of a linear array of three or more closely-spaced metal ions, which are supported by four deprotonated oligopyridylamine (or related) ligands, giving complexes with $D_{4}$ symmetry (Figure 1a). ${ }^{1}$ Such achiral ligands impart chirality to the complexes due to their helicoidal wrapping around the metal axis, arising from the steric hindrance between the protons in the 3-position of the pyridine groups (Figure 1b). ${ }^{2,3,4}$

Racemic mixtures of $\left[\mathrm{CO}_{3}(\mathrm{dpa})_{4}\left(\mathrm{CH}_{3} \mathrm{CN}\right)_{2}\right]^{2+}(\mathrm{dpa}=$ the anion of 2,2'-dipyridylamine) obtained from laboratory synthesis can be resolved with the chiral anion $\left[\mathrm{As}_{2}(\text { tartrate })_{2}\right]^{2-},{ }^{5}(\mathrm{AsT})$, by diastereomeric ion pairing and selective crystallization. ${ }^{6}$ The compounds crystallize in the space group $P_{42}{ }_{2}$ as enantiopure $\left(\mathrm{NBu}_{4}\right)_{2}\left[\mathrm{Co}_{3}(\mathrm{dpa})_{4}\left(\mathrm{CH}_{3} \mathrm{CN}\right)_{2}\right](\mathrm{AsT})_{2}$. [solvent] (1·[solvent]), with Flack parameters statistically equal to zero. The tricobalt complexes display persistent optical activity in solution, as evidenced by electronic circular dichroism (ECD) spectra in $\mathrm{CH}_{3} \mathrm{CN}$, where the dichroism peaks exhibit dissymmetry $(g)$ factors up to $10^{-2}$. It was also shown that the chirality of the $\Delta-\left[\mathrm{Co}_{3}(\mathrm{dpa})_{4}\left(\mathrm{CH}_{3} \mathrm{CN}\right)_{2}\right]^{2+}$ unit was retained upon exchanging AsT with $\mathrm{PF}_{6}{ }^{-}$to form $\Delta-\left[\mathrm{Co}_{3}\left(\mathrm{dpa}_{4}\left(\mathrm{CH}_{3} \mathrm{CN}\right)_{2}\right]\left(\mathrm{PF}_{6}\right)_{2}(\Delta-2)\right.$ crystallizing in the space group $P 2_{1}$ as $\Delta-2 \cdot \mathrm{CH}_{3} \mathrm{CN} \cdot \mathrm{C}_{4} \mathrm{H}_{10} \mathrm{O}$, as shown by X-ray crystallography and ECD. ${ }^{6}$

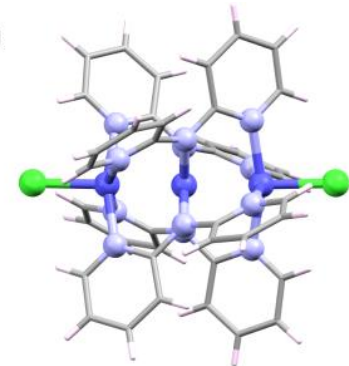

b

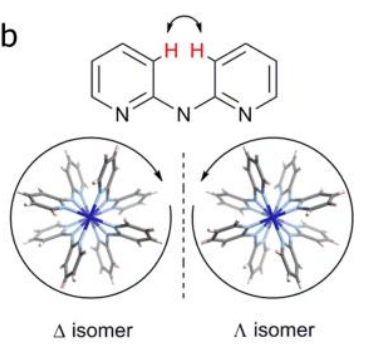

FIGURE 1 a) Depiction of a representative trinuclear paddlewheel complex with the anion of 2,2'-dipyridylamine (dpa). Metal in dark blue, nitrogen in light blue, chloride in green; b) Helicoidal chirality engendered by proton repulsion in the dpa ligand.

This resolution strategy has now been applied to the nickel(II) analogue, $\left[\mathrm{Ni}_{3}(\mathrm{dpa})_{4}\left(\mathrm{CH}_{3} \mathrm{CN}\right)_{2}\right]^{2+}$. It has been recently reported that the combination of AsT and $\left[\mathrm{Ni}_{3}(\mathrm{dpa})_{4}\left(\mathrm{CH}_{3} \mathrm{CN}\right)_{2}\right]^{2+}$ in DMF yields chiral onedimensional coordination polymers constructed of axiallybound AsT linking the trimetal units together in an alternating $\mathrm{Ni}_{3}(\mathrm{dpa})_{4}$-AsT motif. ${ }^{7}$ However, when the reaction is performed in acetonitrile, discrete trinuclear chiral complexes were obtained. These compounds are isostructural with the cobalt(II) congener (1·[solvent]), and crystallize in the space group $P 42_{12} 2$ as $\left(\mathrm{NBu}_{4}\right)_{2}\left[\mathrm{Ni}_{3}(\mathrm{dpa})_{4}\left(\mathrm{CH}_{3} \mathrm{CN}\right)_{2}\right](\text { AsT })_{2}$ :[solvent] (3·[solvent]). The AsT anions in both enantiomers of $1 \cdot$ [solvent] and 3.[solvent] were exchanged with $\mathrm{PF}_{6}{ }^{-}$anions to give 
$\left[\mathrm{Co}_{3}(\mathrm{dpa})_{4}\left(\mathrm{CH}_{3} \mathrm{CN}\right)_{2}\right]\left(\mathrm{PF}_{6}\right)_{2}\left(\Delta\right.$ - and $\Lambda$-2) and $\left[\mathrm{Ni}_{3}(\mathrm{dpa})_{4}\left(\mathrm{CH}_{3} \mathrm{CN}\right)_{2}\right]\left(\mathrm{PF}_{6}\right)_{2}(\Delta$ - and $\Lambda$-4), respectively. Complexes $\Delta$ - and $\Lambda$-2 exhibit mirrorimage vibrational circular dichroism (VCD) spectra, which are characterized by the remarkable intensity of their peaks with $\Delta \varepsilon$ values up to $6 \mathrm{Lmol}^{-1} \mathrm{~cm}^{-1}$ and dissymmetry factors approaching $2 \times 10^{-3}$. Complexes $\Delta$ - and $\Lambda$-4 exhibit similar spectra, but with lower $\Delta \varepsilon$ values (approaching $4 \mathrm{Lmol}^{-1} \mathrm{~cm}^{-1}$ ) and dissymmetry factors of $1 \times 10^{-3}$. DFT calculations well reproduce the peak position, the sign and the relative intensity for the spectra of both compounds, suggesting that the intensity of the peaks cannot be easily attributed to VCD enhancement from low lying excited states (LLES).

\section{Materials and Methods}

\section{SYNTHESIS}

General. Elemental analyses were carried out by the Service d'Analyse Elémentaire of the University of Lorraine (Nancy, France). Routine IR characterization was performed using a Nicolet $6700 \mathrm{FTIR}$ spectrometer between 400 and $4000 \mathrm{~cm}^{-1}$ equipped with an ATR accessory on polycrystalline samples. The synthesis of $\mathbf{1} \cdot\left[\right.$ solvent], $2 \cdot \mathrm{CH}_{3} \mathrm{CN} \cdot \mathrm{C}_{4} \mathrm{H}_{10} \mathrm{O}^{6}$ and $\left(\mathrm{NBu}_{4}\right)_{2}\left[\mathrm{As}_{2}(\operatorname{tartrate})_{2}\right]^{8}$ was accomplished as previously described.

$\left[\mathrm{Ni}_{3}(\mathrm{dpa})_{4} \mathrm{Cl}_{2}\right.$ ]. This compound was synthesized using the literature procedure, ${ }^{9}$ except it was crystallized from $\mathrm{CH}_{2} \mathrm{Cl}_{2}$ and $n$-hexane. The crystals were characterized as $\left[\mathrm{Ni}_{3}(\mathrm{dpa})_{4} \mathrm{Cl}_{2}\right] \cdot 0.67 \mathrm{CH}_{2} \mathrm{Cl}_{2} \cdot 0.33 \mathrm{C}_{6} \mathrm{H}_{14}$ by X-ray diffraction (Tables S1-S3). Crystalline yield: $44 \%$. IR $(\bar{v}$, $\left.\mathrm{cm}^{-1}\right)$ : $3066(\mathrm{w}), 3024(\mathrm{w}), 2969(\mathrm{w}), 2928(\mathrm{w}), 2888(\mathrm{w}), 2849(\mathrm{w}), 2162(\mathrm{w}), 1978(\mathrm{w})$; $1601(\mathrm{~m}), 1590(\mathrm{~s}), 1548(\mathrm{~m}), 1466(\mathrm{~s}), 1457(\mathrm{~s})$, $1438(\mathrm{~m}) ; 1416(\mathrm{~s}), 1360(\mathrm{~m}), 1346(\mathrm{~s}), 1310(\mathrm{~s}), 1280(\mathrm{~m}), 1243(\mathrm{~m}), 1152(\mathrm{~m}), 1103(\mathrm{~m}), 1054(\mathrm{w}), 1014(\mathrm{~m}), 926(\mathrm{w}), 890(\mathrm{~m}), 843(\mathrm{w})$, 765 (s), 741 (s), 640 (m). Anal. calcd. for $\mathrm{Ni}_{3} \mathrm{C}_{40} \mathrm{H}_{32} \mathrm{~N}_{12} \mathrm{Cl}_{2} \cdot 0.67 \mathrm{CH}_{2} \mathrm{Cl}_{2} \cdot 0.33 \mathrm{C}_{6} \mathrm{H}_{14} \cdot 1.5 \mathrm{H}_{2} \mathrm{O}: \mathrm{C} 49.25, \mathrm{H} 3.97, \mathrm{~N} 16.16$; found: C 49.02, H 3.81, N 15.96 .

$\left(\mathrm{NBu}_{4}\right)_{2}\left[\mathrm{Ni}_{3}(\mathrm{dpa})_{4}\left(\mathrm{CH}_{3} \mathrm{CN}\right)_{2}\right](\mathbf{A s T})_{2} \cdot$ [solvent] (3·[solvent]). A solution of $\left[\mathrm{Ni}_{3}(\mathrm{dpa})_{4} \mathrm{Cl}_{2}\right] \cdot 0.67 \mathrm{CH}_{2} \mathrm{Cl}_{2} \cdot 0.33 \mathrm{C}_{6} \mathrm{H}_{14}(0.15 \mathrm{~g}, 0.15 \mathrm{mmol})$ in 2 $\mathrm{mL}$ of $\mathrm{CH}_{3} \mathrm{CN}$ and a solution of silver hexafluorophosphate $(0.080 \mathrm{~g}, 0.32 \mathrm{mmol})$ in $1 \mathrm{~mL}$ of $\mathrm{CH}_{3} \mathrm{CN}$ were combined in a $20 \mathrm{~mL}$ aluminium foil-wrapped vial and stirred overnight in a glovebox. The solution was filtered to eliminate silver chloride and $\Lambda$ - or $\Delta$-AsT $(0.30 \mathrm{~g}, 0.32$ $\mathrm{mmol}$ ), was added to the filtrate. The resultant solution was stirred for $2 \mathrm{~h}$, filtered and set for $\mathrm{Et}_{2} \mathrm{O}$ vapour diffusion. After several days, dark purple crystals were obtained, washed and stored in $\mathrm{Et}_{2} \mathrm{O}$. Yields based on quantity of starting racemate: $\Delta=25 \%, \Lambda=18 \%$, where $\Delta / \Lambda$ labels refer to the handedness of the trinickel complex. IR $\left(\bar{v}, \mathrm{~cm}^{-1}\right): 2962(\mathrm{w}), 2877(\mathrm{w}), 1664(\mathrm{~m}), 1603(\mathrm{~m}), 1592(\mathrm{~m}), 1550(\mathrm{~m})$, $1469(\mathrm{~s}), 1459(\mathrm{~s}), 1423(\mathrm{~s}), 1355(\mathrm{~m}), 1313(\mathrm{~m}), 1283(\mathrm{~m}), 1263(\mathrm{~m}), 1154(\mathrm{~m}), 1128(\mathrm{~m}), 1074(\mathrm{~m}), 1057(\mathrm{~m}), 1016(\mathrm{~m}), 927(\mathrm{w}), 894$ $(\mathrm{m}), 878(\mathrm{~m}), 832(\mathrm{~s}), 763(\mathrm{~s}), 734(\mathrm{~s}), 661(\mathrm{~m}), 638(\mathrm{~m}), 591(\mathrm{w}), 557(\mathrm{~s})$. Anal. calcd. for $\mathrm{Ni}_{3} \mathrm{As}_{4} \mathrm{C}_{92} \mathrm{H}_{118} \mathrm{~N}_{16} \mathrm{O}_{24} \cdot 4 \mathrm{H}_{2} \mathrm{O} \cdot 1.2 \mathrm{Et}_{2} \mathrm{O}: \mathrm{C} 47.09, \mathrm{H}$ 5.63, N 9.08; found: C 46.79, H 5.30, N 8.67.

$\left[\mathrm{Ni}_{3}(\mathrm{dpa})_{4}\left(\mathrm{CH}_{3} \mathrm{CN}\right)_{2}\right]\left(\mathrm{PF}_{6}\right)_{2} \cdot 2 \mathrm{CH}_{3} \mathrm{CN}\left(\mathbf{4} \cdot 2 \mathrm{CH}_{3} \mathrm{CN}\right) . \mathrm{KPF}_{6}(20 \mathrm{mg}, 0.11 \mathrm{mmol})$ and $\Delta-\mathbf{3} \cdot[$ solvent] $(64 \mathrm{mg}, 0.028 \mathrm{mmol})$ were dissolved in 3 $\mathrm{mL} \mathrm{CH} \mathrm{CH}_{3} \mathrm{CN}$ and stirred for $3 \mathrm{~h}$ in a glovebox, filtered and set for $\mathrm{Et}_{2} \mathrm{O}$ vapour diffusion. Purple crystals of $\Delta-\mathbf{4} \cdot 2 \mathrm{CH}_{3} \mathrm{CN}_{\text {were obtained in }}$ $38 \%$ yield. The same reaction, using $55 \mathrm{mg}$ of $\Lambda-3 \cdot$ [solvent] and $17 \mathrm{mg} \mathrm{KPF}$ was used to obtain $\Lambda-4 \cdot 2 \mathrm{CH}_{3} \mathrm{CN}$ in $24 \%$ yield. Anal. calcd. for $\mathrm{Ni}_{3} \mathrm{P}_{2} \mathrm{C}_{44} \mathrm{H}_{38} \mathrm{~N}_{14} \mathrm{~F}_{12} \cdot \mathrm{CH}_{3} \mathrm{CN}$ : C 43.51, H 3.25; N 16.54; found: C 43.36, H 3.32, N, 16.67.

\section{PHYSICAL MEASUREMENTS}

X-ray Crystallography. Crystals suitable for X-ray diffraction were selected under immersion oil in ambient conditions and attached to a MiTeGen microloop. The crystals were mounted in a stream of cold nitrogen at $120(2) \mathrm{K}$ and centered in the X-ray beam using a video camera. Data collections were performed with Mo Ka $(\lambda=0.71073 \AA)$ radiation on a Bruker Quazar SMART APEXII, operating at $50 \mathrm{kV}$ and $30 \mathrm{~mA}$ using graphite monochromated radiation. The data were collected using a routine to survey reciprocal space, and reduction and a semi-empirical absorption correction was performed using software included in the Bruker Apex 2 suite. ${ }^{10}$ The structures were solved using direct methods, ${ }^{11}$ except for $4 \cdot 2 \mathrm{CH}_{3} \mathrm{CN}$, which used intrinsic phasing. ${ }^{12}$ Non-hydrogen atoms were refined anisotropically using weighted full-matrix least-squares on $F^{2}$, followed by difference Fourier synthesis using Olex $2 .{ }^{13}$ Flack parameters were calculated using Parson's quotients method. All hydrogen atoms were included in the final structure factor calculation at idealized positions and were allowed to ride on the neighboring atoms with relative isotropic displacement coefficients. The Olex 2 solvent mask routine was used to account for diffuse electron density arising from the interstitial solvent that could not be modeled in 3·[solvent]. CCDC 1969385-1969389 contain the crystallographic data for this paper. These data can be obtained free of charge from the Cambridge Crystallographic Data Centre via www.ccdc.cam.ac.uk/data_request/cif.

Solution IR and VCD measurements. The IR and VCD spectra of the enantiomers of 2 and $\mathbf{4}$ were recorded on a FTIR spectrometer equipped with a VCD optical bench. ${ }^{14}$ Spectra were recorded at a resolution of $4 \mathrm{~cm}^{-1}$, by coadding 50 and $24000 \mathrm{scans}$ ( $8 \mathrm{~h}$ acquisition time), respectively. Samples were prepared in $\mathrm{CD}_{3} \mathrm{CN}$ at a concentration of $12.5 \mathrm{mM}$ and measured in a $115 \mu \mathrm{m}$ path length cell with $\mathrm{BaF}_{2}$ windows.

\section{THEORETICAL CALCULATIONS}

Geometry optimizations, vibrational frequencies and absorption intensities were calculated using Gaussian 16 on the DELL cluster of the MCIA computing centre of Bordeaux University. ${ }^{15}$ The X-ray geometry of $\Delta-\mathbf{2}$ and $\Delta-\mathbf{4}$ was used, and the structures were simplified by 


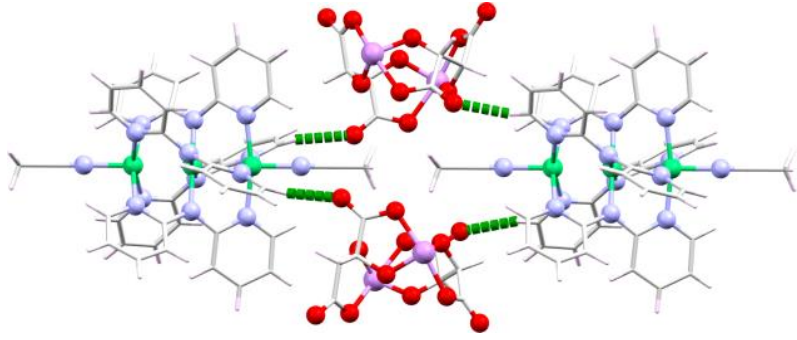

FIGURE 2 Representation of the short contacts (dashed green lines, $2.365 \AA$ ) between $\left[\mathrm{Ni}_{3}(\mathrm{dpa})_{4}\left(\mathrm{CH}_{3} \mathrm{CN}\right)_{2}\right]^{2+}$ and AsT in $\Delta-3 \cdot$ [solvent] from X-ray data. Nickel (green), arsenic (purple), nitrogen (blue), oxygen (red), carbon (gray), hydrogen (pink). replacing the axial acetonitrile ligand with a chloride ligand and removing the $\mathrm{PF}_{6}{ }^{-}$counter anions. These model complexes were used due to a lack of satisfactory convergence in the geometry optimization of the cationic acetonitrile adducts. Geometry optimizations (Figures S1 and S2) were performed at the density functional theory (DFT) level using the B3LYP functional and $6-31 G^{* *}$ basis set with the Gaussian 16 package considering spin states of $S=1 / 2$ for the $\mathrm{Co}$ (II) analogue and $S=2$ for the $\mathrm{Ni}$ (II) analogue. For the nickel compound, we found that when two $S=1$ centers were localized on the terminal ions,

this simple "ferromagnetic" model with total spin $S=2$ gave the best agreement with the crystal structure (Table S9) and the VCD spectrum, compared to the models with $S=0$ or $S=1$. IR and VCD intensities and frequencies were calculated at the same level of theory. For comparison to experiments, the calculated frequencies were scaled by 0.968 and the calculated intensities were converted to Lorentzian bands with a half-width of $4 \mathrm{~cm}^{-1}$.

\section{Results and Discussion}

\section{SYNTHESIS AND CRYSTAL STRUCTURES}

Resolution of $\left[\mathrm{Ni}_{3}(\mathrm{dpa})_{4}\left(\mathrm{CH}_{3} \mathrm{CN}\right)_{2}\right]^{2+}$ enantiomers. The resolution of the trinickel complex was undertaken following the same strategy as used for the tricobalt complex $\left[\mathrm{Co}_{3}(\mathrm{dpa})_{4} \mathrm{Cl}_{2}\right]$, involving the conversion of racemic $\left[\mathrm{Ni}_{3}\left(\mathrm{dpa}_{4} \mathrm{Cl}_{2}\right]\right.$ to the $\mathrm{PF}_{6}{ }^{-}$salt $\left[\mathrm{Ni}_{3}(\mathrm{dpa})_{4}\left(\mathrm{CH}_{3} \mathrm{CN}\right)_{2}\right]\left(\mathrm{PF}_{6}\right)_{2}$, followed by preferential crystallization with enantiopure arsenyl tartrate anions (AsT). ${ }^{6}$ Specifically, acetonitrile solutions of $\left[\mathrm{Ni}_{3}(\mathrm{dpa})_{4} \mathrm{Cl}_{2}\right]$ and silver hexafluorophosphate were combined and stirred overnight. After filtration of the solution to remove $\mathrm{AgCl}$, the tetrabutylammonium salt of $\Lambda$-AsT or $\Delta$-AsT was added. After stirring for about two hours, the solution was filtered and placed in a vial which was placed in a larger vial of $\mathrm{Et}_{2} \mathrm{O}$, yielding dark purple crystals after several days of $\mathrm{Et}_{2} \mathrm{O}$ vapor diffusion. The crystalline yield, based on the starting trinickel complex, averaged $22 \%$, corresponding to a low-to-moderate yield of $44 \%$ with respect to a given enantiomer.

TABLE 1 Crystal data and structure refinement for $\Delta-3 \cdot[$ solvent] and $\Lambda-3 \cdot[$ solvent].

\begin{tabular}{|c|c|c|c|c|}
\hline & \multicolumn{2}{|l|}{$\Delta-3 \cdot[$ solvent] } & \multicolumn{2}{|l|}{$\Lambda-3 \cdot[$ solvent] } \\
\hline Formula & \multicolumn{2}{|l|}{$\mathrm{C}_{92} \mathrm{H}_{118} \mathrm{~N}_{16} \mathrm{O}_{24} \mathrm{As}_{4} \mathrm{Ni}_{3}$} & \multicolumn{2}{|l|}{$\mathrm{C}_{92} \mathrm{H}_{118} \mathrm{~N}_{16} \mathrm{O}_{24} \mathrm{As}_{4} \mathrm{Ni}_{3}$} \\
\hline FW & \multicolumn{2}{|l|}{2307.82} & \multicolumn{2}{|l|}{2307.82} \\
\hline$T / \mathrm{K}$ & \multicolumn{2}{|l|}{$120(2)$} & \multicolumn{2}{|l|}{$120(2)$} \\
\hline$\lambda / \AA$ & \multicolumn{2}{|l|}{0.71073} & \multicolumn{2}{|l|}{0.71073} \\
\hline Crystal system, space group & \multicolumn{2}{|l|}{ Tetragonal, $P 42,2$} & \multicolumn{2}{|l|}{ Tetragonal, $P 42_{1} 2$} \\
\hline Unit cell dimensions ( $\AA$ and deg.) & $\begin{array}{l}a=20.6415(6) \\
b=20.6415(6) \\
c=16.8676(5)\end{array}$ & $\begin{array}{l}\alpha=90 \\
\beta=90 \\
\gamma=90\end{array}$ & $\begin{array}{l}a=20.6668(10) \\
b=20.6668(10) \\
c=16.8568(9)\end{array}$ & $\begin{array}{l}\alpha=90 \\
\beta=90 \\
\gamma=90\end{array}$ \\
\hline$V / \AA^{3}$ & \multicolumn{2}{|l|}{$7186.8(4)$} & \multicolumn{2}{|l|}{$7199.8(4)$} \\
\hline$Z, \rho_{\text {calc }} / \mathrm{g} \mathrm{cm}^{-3}$ & \multicolumn{2}{|l|}{$2,1.0664$} & \multicolumn{2}{|l|}{$2,1.0645$} \\
\hline$\mu / \mathrm{mm}^{-1}$ & \multicolumn{2}{|l|}{1.358} & \multicolumn{2}{|l|}{1.356} \\
\hline$F(000)$ & \multicolumn{2}{|l|}{2383.7} & \multicolumn{2}{|l|}{2383.7} \\
\hline Cryst. size $/ \mathrm{mm}^{3}$ & \multicolumn{2}{|l|}{$0.24 \times 0.11 \times 0.10$} & \multicolumn{2}{|l|}{$0.36 \times 0.32 \times 0.14$} \\
\hline $2 \theta$ range / deg. & \multicolumn{2}{|l|}{2.80 to 53.02} & \multicolumn{2}{|l|}{3.68 to 50.76} \\
\hline Limiting indices & \multicolumn{2}{|l|}{$\begin{array}{l}-25 \leq \mathrm{h} \leq 25 \\
-25 \leq \mathrm{k} \leq 25 \\
-21 \leq \mathrm{I} \leq 21\end{array}$} & \multicolumn{2}{|l|}{$\begin{array}{l}-24 \leq h \leq 24 \\
-24 \leq k \leq 24 \\
-20 \leq 1 \leq 20\end{array}$} \\
\hline Reflections collected/unique & \multicolumn{2}{|l|}{$\begin{array}{l}217136 / 7458 \\
{\left[\mathrm{R}_{\text {int }}=0.0715\right]}\end{array}$} & \multicolumn{2}{|l|}{$\begin{array}{l}101684 / 6628 \\
{\left[R_{\text {int }}=0.0355\right]}\end{array}$} \\
\hline $\begin{array}{l}\text { Data/restraints/parameters } \\
\text { GooF on } F^{2}\end{array}$ & \multicolumn{2}{|l|}{7458 / 0 / 321} & \multicolumn{2}{|l|}{$6628 / 0 / 321$} \\
\hline$R$ indices [all data] ${ }^{a}$ & \multicolumn{2}{|l|}{$\begin{array}{l}R_{1}=0.0404 \\
w R_{2}=0.0906\end{array}$} & \multicolumn{2}{|l|}{$\begin{array}{l}R_{1}=0.0375 \\
w R_{2}=0.0921\end{array}$} \\
\hline Flack parameter & \multicolumn{2}{|l|}{$0.013(19)$} & \multicolumn{2}{|l|}{$0.02(2)$} \\
\hline
\end{tabular}


TABLE 2 Selected average atom distances $(\AA)$ and angles (deg.) for $4 \cdot 3.14 \mathrm{CH}_{3} \mathrm{CN}, \mathbf{3} \cdot\left[\right.$ solvent] and $4 \cdot 2 \mathrm{CH}_{3} \mathrm{CN}$. Average values indicated by standard deviations in brackets.

\begin{tabular}{lllllll}
\hline & $4 \cdot 3.14 \mathrm{CH}_{3} \mathrm{CN}$ & $\Delta-3 \cdot[$ solvent] & $\Lambda-3 \cdot[$ solvent] & $\Delta-4 \cdot 2 \mathrm{CH}_{3} \mathrm{CN}$ & $\Lambda-4 \cdot 2 \mathrm{CH}{ }_{3} \mathrm{CN}$ \\
\hline $\mathrm{Ni}-\mathrm{Ni}$ & $2.3743[2]$ & $2.3869(4)$ & $2.3909(5)$ & $2.3847(3)$ & $2.3838(3)$ \\
\hline $\mathrm{Ni}-\mathrm{NC} \mathrm{CH}_{3}$ & $2.049[7]$ & $1.977(3)$ & $2.004(4)$ & $2.0231(17)$ & $2.0239(12)$ \\
\hline $\mathrm{Ni}_{\mathrm{T}}-\mathrm{N}$ & $2.079[7]$ & $2.072[2]$ & $2.080[3]$ & $2.0830[18]$ & $2.0830[13]$ \\
\hline $\mathrm{Ni}{ }_{\mathrm{C}}-\mathrm{N}$ & $1.882[8]$ & $1.881[3]$ & $1.885[3]$ & $1.8872[18]$ & $1.8887[13]$ \\
\hline $\mathrm{Ni}-\mathrm{Ni}-\mathrm{Ni}$ & $179.06(6)$ & 180.0 & 180.0 & $179.65(2)$ & $179.665(15)$ \\
\hline $\mathrm{Ni}-\mathrm{N}_{\mathrm{ax}}-\mathrm{C} \mathrm{CH}_{3}$ & $174[1]$ & 180.0 & 180.0 & $169.3(2)$ & $169.17(16)$ \\
\hline
\end{tabular}

The enantiomorphic compounds consist of a complex with three aligned nickel ions wrapped by four dpa ligands and a $\mathrm{CH}_{3} \mathrm{CN}$ molecule in each of the axial positions, along with AsT and tetrabutylammonium molecules present as counterions, giving the formula $\left(\mathrm{NBu}_{4}\right)_{2}\left[\mathrm{Ni}_{3}(\mathrm{dpa})_{4}\left(\mathrm{CH}_{3} \mathrm{CN}\right)_{2}\right](\mathrm{AsT})_{2}$ [ [solvent] (3-[solvent]). The trinickel complex is a dication while the AsT complex is a dianion; therefore a 1:1 stoichiometric relationship might be expected. Instead, the stoichiometry is $1: 2$ between the nickel complex and the arsenyl tartrate, with two tetrabutylammonium monocations balancing the charge. The interactions between the nickel cations and the arsenyl anions are heterochiral in the sense that the $\Delta$ enantiomer of the paddlewheel unit is associated with the $\Lambda$ enantiomer of the AsT anion, and vice versa. This interaction is principally maintained by short contacts between pyridyl carbon atoms of the cation and $\mathrm{O}$ atoms of the anion (Figure 2).

Crystal structures for both enantiomers of 3 were solved in the tetragonal space group $P 422_{1}$ and are isostructural with those previously reported for the cobalt analogues (Table 1). ${ }^{6}$ Flack parameters of $0.013(19)$ for those of $\Delta-3$ and $0.02(2)$ for $\Lambda-3$ demonstrate that the enantiopurity is high. Residual Q-peaks too diffuse to be assigned were attributed to highly disordered $\mathrm{Et}_{2} \mathrm{O}$ solvent molecules, as rigid $\mathrm{CH}_{3} \mathrm{CN}$ solvent molecules would not be expected to present such disorder. The solvent mask routine in Olex $2^{13}$ indicated the presence of a single solvent-accessible void of $2848 \AA^{3}$ containing $490 \mathrm{e}^{-}$for $\Delta-3$ and a void of $2832 \AA^{3}$ containing $525 \mathrm{e}^{-}$for $\Lambda-3$. The electron density here is lower than that observed for $1\left(\sim 550 \mathrm{e}^{-}\right),{ }^{6}$ but this can be explained by solvent loss at room temperature as indicated by the thermogravimetric analysis for both 1 and 3 . The electron density corresponds to approximately six $\mathrm{Et}_{2} \mathrm{O}$ molecules $(252$ $\left.\mathrm{e}^{-}\right)$per formula unit $(Z=2)$, consistent with the TGA mass loss of $15 \%$ before decomposition upon heating (Figure S3). Having no atomistic model of the solvents of crystallization, compound $\mathbf{3}$ in the solid state is referred to as 3.[solvent], in analogy with previously reported $\mathbf{1} \cdot\left[\right.$ solvent]. ${ }^{6}$

The structure of $3 \cdot$ [solvent] can be compared with previously reported racemic $\left[\mathrm{Ni}_{3}(\mathrm{dpa})_{4}\left(\mathrm{CH}_{3} \mathrm{CN}\right)_{2}\right]\left(\mathrm{PF}_{6}\right)_{2} \cdot 3.14 \mathrm{CH}_{3} \mathrm{CN} \quad(\mathbf{4} \cdot 3.14$ $\left.\mathrm{CH}_{3} \mathrm{CN}\right) .{ }^{16}$ In $3 \cdot$ [solvent], the asymmetric unit consists of one quarter of the nickel complex, half of the arsenyl tartrate dianion and half of the tetrabutylammonium cation. The two $\mathrm{Ni}-\mathrm{Ni}$ distances are thus crystallographically equivalent (with an average of $2.389 \AA$ for the two enantiomers). In $4 \cdot 3.14 \mathrm{CH}_{3} \mathrm{CN}$, the entire molecule is present in the asymmetric unit, with similar Ni-Ni distances of 2.375 and $2.371 \AA$. The slightly longer Ni-Ni distances in 3.[solvent] are concomitant with shorter distances between the terminal nickel ions and the axial nitrogen atoms (2.045 and $2.053 \AA$ in $4.3 .14 \mathrm{CH}_{3} \mathrm{CN}$ vs an average of $1.991 \AA$ in $3 \cdot$ [solvent]). In 3.[solvent] the angle formed by the three metal atoms and the acetonitrile molecules is perfectly linear, in $4 \cdot 3.14 \mathrm{CH}_{3} \mathrm{CN}$, an angle of $179.06^{\circ}$ in the trimetallic array and angles of $172.78^{\circ}$ and $175.35^{\circ}$ between the metallic array and the axial ligands were observed. Regarding the distances between the nickel ions and the nitrogen atoms of the dpa ligands, no notable differences were found. A comparison between selected atom distances and angles is presented in Table 2 and a more complete list for 3.[solvent] is given in Tables S4-S6.

With regard to the packing of the molecules in $3 \cdot$ [solvent], the trinickel chains are oriented with their metallic axis parallel to the crystallographic $c$ axis. Layers of $\left[\mathrm{Ni}_{3}(\mathrm{dpa})_{4}\left(\mathrm{CH}_{3} \mathrm{CN}\right)_{2}\right]^{2+}$ are formed in the $a b$ plane, and are separated by a layer of $\mathrm{AsT}$ anions and $\mathrm{NBu}_{4}$ cations (Figure 3 ). This lamellar packing results in a two-dimensional solvent-accessible void, which accounts for the mobility of the solvent in the crystal structure. Viewing along the $c$ axis (Figure 3 ) the $\left[\mathrm{Ni}_{3}(\mathrm{dpa})_{4}\left(\mathrm{CH}_{3} \mathrm{CN}\right)_{2}\right]^{2+}$ units are separated by two AsT anions and two $\mathrm{NBu}_{4}$ cations positioned opposite one another forming a solventinaccessible capsule around the axial position of the trinuclear unit.

a
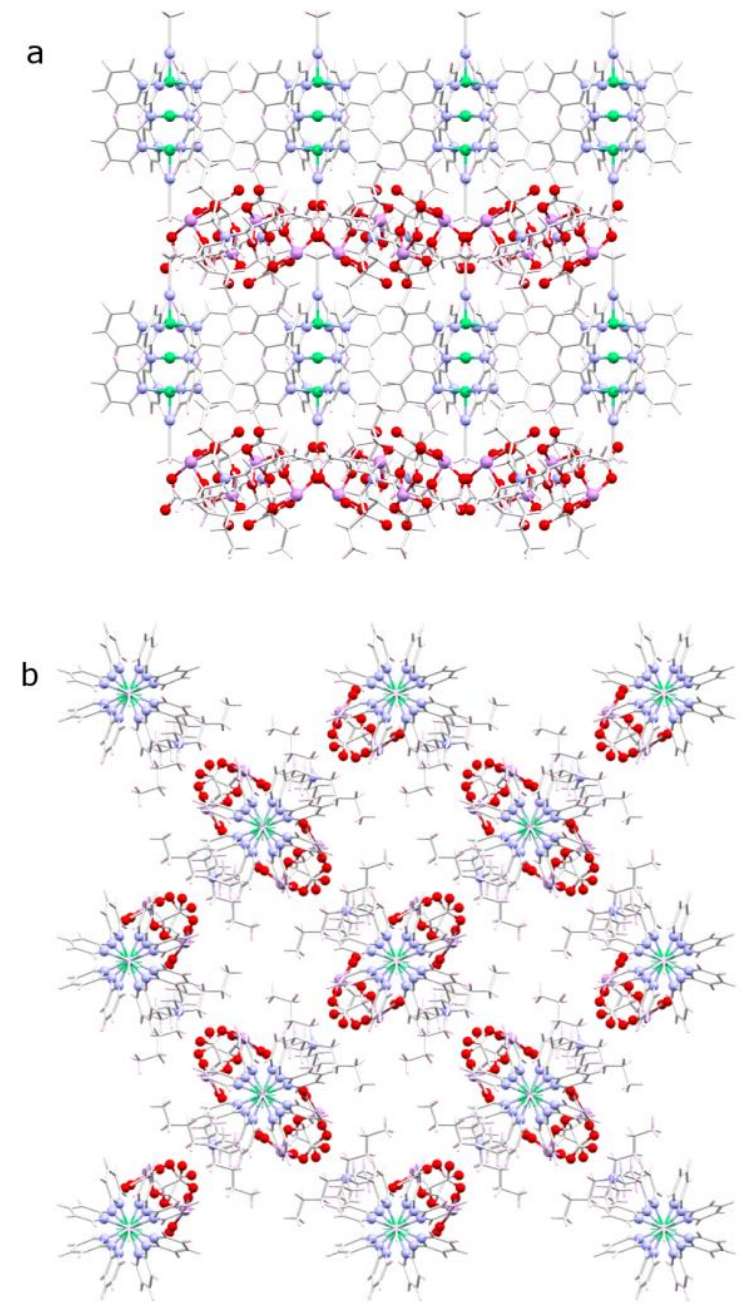

FIGURE 3 Crystal packing of $\Delta-3 \cdot$ [solvent], A) along the a axis, B) along the $c$ axis. 
TABLE 3 Crystal data and structure refinement for $\Delta-4 \cdot 2 \mathrm{CH}_{3} \mathrm{CN}$ and $\Lambda-4 \cdot 2 \mathrm{CH}_{3} \mathrm{CN}$.

\begin{tabular}{|c|c|c|c|c|}
\hline & \multicolumn{2}{|l|}{$\Delta-4 \cdot 2 \mathrm{CH}_{3} \mathrm{CN}$} & \multicolumn{2}{|l|}{$\Lambda-4 \cdot 2 \mathrm{CH}_{3} \mathrm{CN}$} \\
\hline Formula & \multicolumn{2}{|l|}{$\mathrm{C}_{48} \mathrm{H}_{44} \mathrm{~N}_{16} \mathrm{~F}_{12} \mathrm{P}_{2} \mathrm{Ni}_{3}$} & \multicolumn{2}{|l|}{$\mathrm{C}_{48} \mathrm{H}_{44} \mathrm{~N}_{16} \mathrm{~F}_{12} \mathrm{P}_{2} \mathrm{Ni}_{3}$} \\
\hline FW & \multicolumn{2}{|l|}{1311.00} & \multicolumn{2}{|l|}{1311.00} \\
\hline$T / \mathrm{K}$ & \multicolumn{2}{|l|}{$120(2)$} & \multicolumn{2}{|l|}{$120(2)$} \\
\hline$\lambda / \AA$ & \multicolumn{2}{|l|}{0.71073} & \multicolumn{2}{|l|}{0.71073} \\
\hline Crystal system, space group & \multicolumn{2}{|l|}{ Monoclinic, $C 2$} & \multicolumn{2}{|l|}{ Monoclinic, $C 2$} \\
\hline Unit cell dimensions ( $\AA \dot{A}$ and deg.) & $\begin{array}{l}a=16.1969(15) \\
b=16.6318(14) \\
c=11.7335(11)\end{array}$ & $\begin{array}{l}\alpha=90 \\
\beta=120.462(4) \\
\gamma=90\end{array}$ & $\begin{array}{l}a=16.1847(14) \\
b=16.6245(15) \\
c=11.7246(11)\end{array}$ & $\begin{array}{l}\alpha=90 \\
\beta=120.505(4) \\
\gamma=90\end{array}$ \\
\hline$V / \AA^{3}$ & \multicolumn{2}{|l|}{$2724.5(4)$} & \multicolumn{2}{|l|}{$2718.0(4)$} \\
\hline$Z, \rho_{\text {calc }} / \mathrm{g} \mathrm{cm}^{-3}$ & \multicolumn{2}{|l|}{$2,1.5979$} & \multicolumn{2}{|l|}{$2,1.6018$} \\
\hline$\mu / \mathrm{mm}^{-1}$ & \multicolumn{2}{|l|}{1.177} & \multicolumn{2}{|l|}{1.180} \\
\hline$F(000)$ & \multicolumn{2}{|l|}{1335.2} & \multicolumn{2}{|l|}{1335.2} \\
\hline Cryst. size / mm $\mathrm{mm}^{3}$ & \multicolumn{2}{|l|}{$0.15 \times 0.12 \times 0.07$} & \multicolumn{2}{|l|}{$0.29 \times 0.13 \times 0.09$} \\
\hline $2 \theta$ range / deg. & \multicolumn{2}{|l|}{3.80 to 52.82} & \multicolumn{2}{|l|}{3.82 to 61.08} \\
\hline Limiting indices & \multicolumn{2}{|l|}{$\begin{array}{l}-20 \leq h \leq 20 \\
-20 \leq k \leq 20 \\
-14 \leq 1 \leq 14\end{array}$} & \multicolumn{2}{|l|}{$\begin{array}{l}-23 \leq h \leq 23 \\
-23 \leq k \leq 23 \\
-16 \leq 1 \leq 16\end{array}$} \\
\hline Reflections collected/unique & \multicolumn{2}{|c|}{$43583 / 5591\left[R_{\text {int }}=0.0367\right]$} & \multicolumn{2}{|c|}{$97269 / 8303\left[R_{\text {int }}=0.0456\right]$} \\
\hline Data/restraints/parameters & \multicolumn{2}{|l|}{$5591 / 1 / 369$} & \multicolumn{2}{|l|}{$8303 / 1 / 369$} \\
\hline GooF on $F^{2}$ & \multicolumn{2}{|l|}{1.058} & \multicolumn{2}{|l|}{1.052} \\
\hline $\mathrm{R}$ indexes [all data] ${ }^{a}$ & \multicolumn{2}{|l|}{$\begin{array}{l}R_{1}=0.0246 \\
w R_{2}=0.0592\end{array}$} & \multicolumn{2}{|l|}{$\begin{array}{l}R_{1}=0.0302 \\
w R_{2}=0.0627\end{array}$} \\
\hline Flack parameter & \multicolumn{2}{|l|}{$0.016(9)$} & \multicolumn{2}{|l|}{$0.009(7)$} \\
\hline
\end{tabular}

Preparation of $\left[\mathrm{M}_{3}(\mathrm{dpa})_{4}\left(\mathrm{CH}_{3} \mathrm{CN}\right)_{2}\right]\left(\mathrm{PF}_{6}\right)_{2}$. It has previously been shown that an exchange of AsT for $\mathrm{PF}_{6}{ }^{-}$could be effectuated for $\Delta-1$ without any loss of chirality. ${ }^{6}$ Using the same protocol, $\Delta$ - or $\Lambda-3$ was dissolved in $\mathrm{CH}_{3} \mathrm{CN}$ and treated with 5 eq. of $\mathrm{KPF}_{6}$. After filtration and crystallization with diethyl ether, $\Delta$ - or $\Lambda$ - $\left[\mathrm{Ni}_{3}(\mathrm{dpa})_{4}\left(\mathrm{CH}_{3} \mathrm{CN}\right)_{2}\right]\left(\mathrm{PF}_{6}\right)_{2} \cdot 2 \mathrm{CH}_{3} \mathrm{CN}\left(4 \cdot 2 \mathrm{CH}_{3} \mathrm{CN}\right)$, crystallizing in the non-centrosymmetric space group $\mathrm{C2}$, was obtained in moderate yield. Crystals of the two enantiomers of the cobalt compound $2 \cdot \mathrm{CH} \mathrm{H}_{3} \mathrm{CN} \cdot \mathrm{C}_{4} \mathrm{H}_{10} \mathrm{O}$ were obtained similarly in good yield and have the same crystal structure as those obtained by spontaneous resolution by Cotton and coworkers. ${ }^{2}$

In the structure of $4 \cdot 2 \mathrm{CH}_{3} \mathrm{CN}$, the trinickel complex sits on a special position, with its central $\mathrm{Ni}$ ion being bisected by the 2 -fold axis. The Flack parameters, $0.016(9)(\Delta)$ and $0.009(7)(\Lambda)$, are consistent with the assigned absolute structure and show good crystalline enantiopurity (Table 3 ). It is worthwhile to compare the structures of $4 \cdot 2 \mathrm{CH}_{3} \mathrm{CN}$ with $2 \cdot \mathrm{CH}_{3} \mathrm{CN} \cdot \mathrm{C}_{4} \mathrm{H}_{10} \mathrm{O}$. Surprisingly, these compounds are not isostructural, with $2 \cdot \mathrm{CH}_{3} \mathrm{CN} \cdot \mathrm{C}_{4} \mathrm{H}_{10} \mathrm{O}$ crystallizing in the space group $P 2_{1}$ and $4 \cdot 2 \mathrm{CH}_{3} \mathrm{CN}$ crystallizing in space group $C 2$. In the cobalt compound, the trinuclear complexes are packed in a zig zag fashion along the $b$ axis, while in $4 \cdot 2 \mathrm{CH}_{3} \mathrm{CN}$, the metal axes are all aligned parallel to one another (Figure 4). Selected bond distances and angles for $4.2 \mathrm{CH}_{3} \mathrm{CN}$ are reported in Table 2, with a more complete list provided in Tables S7 and S8. The Ni-Ni distances of $2.384 \AA$ fall between those observed in $4 \cdot 3.14 \mathrm{CH}_{3} \mathrm{CN}$ and 3. [solvent], with a corresponding intermediate distance between the terminal nickel ions and the axial nitrogen atoms.

Electronic circular dichroism (ECD) experiments at room temperature in $\mathrm{CH}_{3} \mathrm{CN}$ show that the anion exchange is effected in 4 with no loss of chirality (Figure S4). Futhermore, no loss in ECD intensity is observed for $\mathbf{3}$ or $\mathbf{4}$ over at least one week (Figure S5). While the crystalline enantiopurity of these complexes was confirmed by X-ray crystallography, the enantiomeric excess (ee) of bulk samples of the two enantiomers of $\mathbf{4}$ was not directly determined. Armstrong and coworkers reported the resolution of the neutral $\left[\mathrm{Ni}_{3}(\mathrm{dpa})_{4} \mathrm{Cl}_{2}\right]$ enantiomers using chiral HPLC. ${ }^{3}$ However, the reported $\Delta \varepsilon$ values in the ECD spectra for the two enantiomers were quite dissimilar $\left(\Delta \varepsilon\right.$ values close to +300 and $-350 \mathrm{Lmol}^{-1} \mathrm{~cm}^{-1}$ for the peak at $368 \mathrm{~nm}$ ), and thus are only approximations of the standard value for an authentic sample.

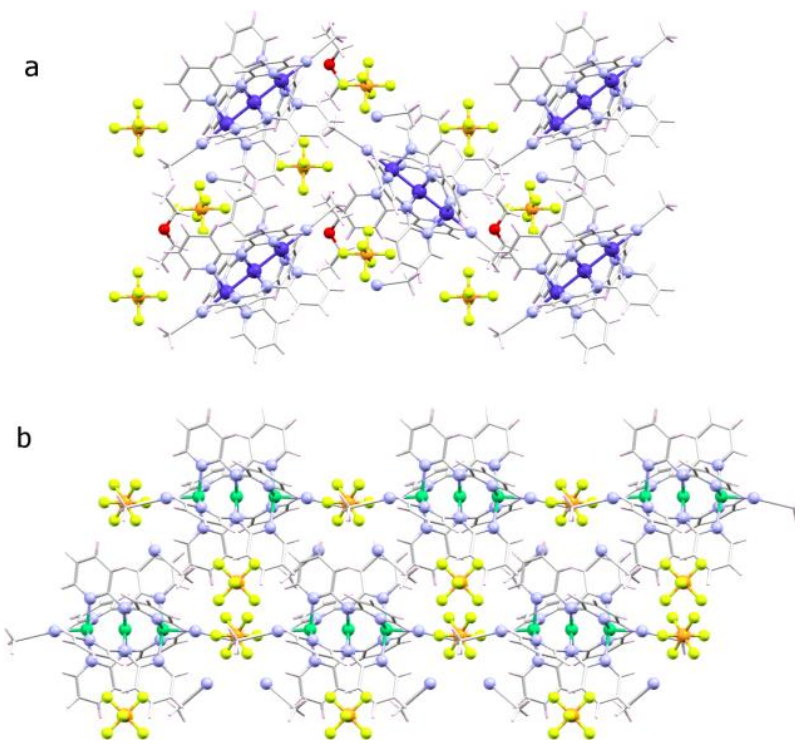

FIGURE 4 Packing diagrams of a) $2 \cdot \mathrm{CH}_{3} \mathrm{CN} \cdot \mathrm{C}_{4} \mathrm{H}_{10} \mathrm{O}$ along the $a$ axis and b) $4 \cdot 2 \mathrm{CH}_{3} \mathrm{CN}$ along the $c$ axis. Cobalt (dark blue), nickel (green), phosphorous (orange), fluorine (yellow) and other atoms their usual colors. 

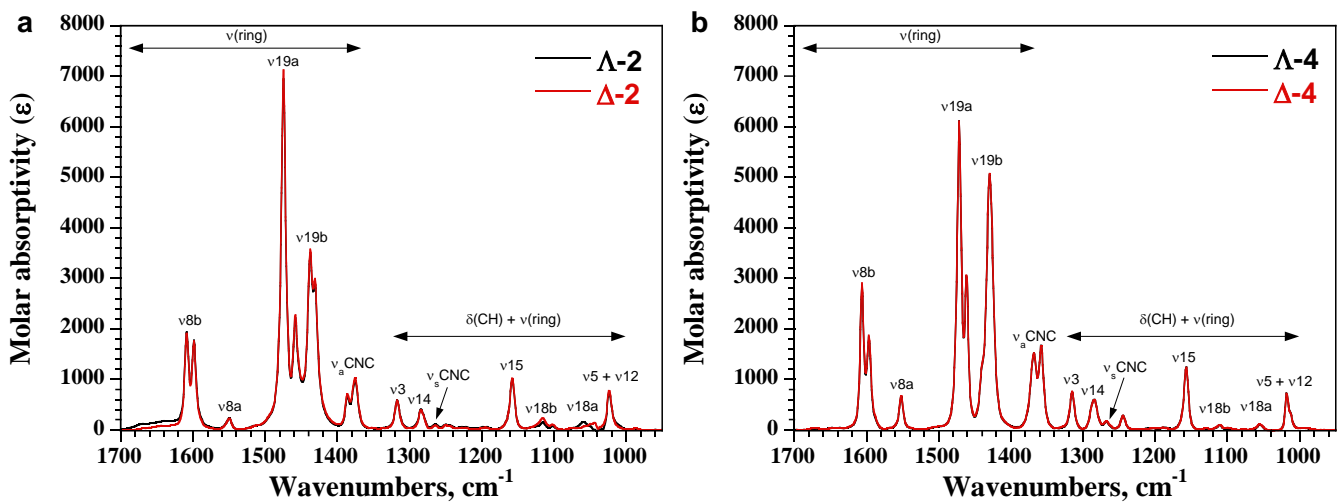

FIGURE 5 IR spectra of a) 2 and b) 4 in $\mathrm{CD}_{3} \mathrm{CN}$.

\section{VIBRATIONAL CIRCULAR DICHROISM}

The chiroptical properties of 2 and 4 were investigated by IR and VCD in $12.5 \mathrm{mM} \mathrm{CD}_{3} \mathrm{CN}$ solutions. The IR spectra of 2 and 4 are reported in the $950-1700 \mathrm{~cm}^{-1}$ spectral range in Figures $5 \mathrm{a}$ and $5 \mathrm{~b}$, respectively. All the bands observed in this spectral range come from the dpa ligand. The assignment of spectral bands for the free ligand $\mathrm{Hdpa}$ as well as for the $\left[\mathrm{M}_{3}(\mathrm{dpa})_{4} \mathrm{X}_{2}\right](\mathrm{M}=\mathrm{Cr}, \mathrm{Co}, \mathrm{Ni}$ and $\mathrm{X}=\mathrm{Cl}$, NCS) complexes have been reported in the literature using the Wilson notation for the vibrational modes of the pyridyl group. ${ }^{17,18}$ The experimental IR spectra are perfectly reproduced by the DFT calculations on neutral model compounds with chloride in the axial position in the gas-phase, as shown in Figure $\mathrm{S} 6$ for $\Delta$-2. The relative intensities and wavenumbers of the pyridyl bands are in good agreement with those calculated, suggesting that the models are appropriate and that more elaborate calculations (specific interactions of the $\mathrm{CD}_{3} \mathrm{CN}$ molecules, more extended basis set) are unnecessary. The agreement of the optimized atomic distances with the crystal structures are acceptable, as detailed in Table S9.

The bands observed between 1400 and $1650 \mathrm{~cm}^{-1}$ are related to the $C=C$ stretching vibrations of the rings ( $v_{8 a}, v_{8 b}, v_{19 a}$ and $\left.v_{19 b}\right)$, whereas the bands between 1000 and $1340 \mathrm{~cm}^{-1}$ are associated with coupled $\mathrm{C}-\mathrm{H}$ in-plane bending and $\mathrm{C}-\mathrm{C}$ stretching vibrations of the rings $\left(v_{3}, v_{15}, v_{18 a}\right.$ and $\left.v_{18 b}\right)$ and to coupled $\mathrm{C}-\mathrm{H}$ out-of-plane bending and $\mathrm{C}-\mathrm{C}$ stretching vibrations of the rings $\left(v_{5}\right)$. The $\mathrm{C}-\mathrm{N}-\mathrm{C}$ symmetric and asymmetric stretching modes are located at 1264 and $1375 \mathrm{~cm}^{-1}$ for 2 and at 1268 and $1358 \mathrm{~cm}^{-1}$ for 4 , respectively. The presence of a single component at $1157 \mathrm{~cm}^{-1}$ for the $v_{15}$ mode reveals the symmetric structure of the two pyridyl groups with similar M-M bond distances. Indeed, Cotton and coworkers have shown that the asymmetric structure of the two pyridyl groups is associated with the presence of a second component at higher wavenumbers $\left(\mathrm{ca} .1167 \mathrm{~cm}^{-1}\right) .{ }^{19}$ It is noteworthy that high values of molar absorptivity (approaching $7000 \mathrm{Lmol}^{-1} \mathrm{~cm}^{-1}$ for the $v_{19 a}$ mode) are obtained for the two complexes.

The VCD spectra of 2 and 4 are reported in the $950-1700 \mathrm{~cm}^{-1}$ spectral range in Figures $6 \mathrm{a}$ and $6 \mathrm{~b}$, respectively. For the cobalt complex, the VCD spectra of the two enantiomers are perfect mirror images with respect to the baseline, revealing identical enantiomeric excess for the two enantiomers. For the nickel analogue, the VCD for the $\Lambda$ enantiomer is 1.25 times stronger than for the $\Delta$ enantiomer, thus demonstrating a lower enantiomeric excess for the latter. Spectral artefacts occur in the $1020-1060 \mathrm{~cm}^{-1}$ region due to the strong absorption interference of the $\mathrm{CD}_{3} \mathrm{CN}$ solvent (strong band at $1038 \mathrm{~cm}^{-1}$ ). The VCD spectra of the two enantiomers of 4 are similar in shape to those published by Armstrong et al. for $\left[\mathrm{Ni}_{3}(\mathrm{dpa})_{4} \mathrm{Cl}_{2}\right.$ ], except the intensity of the VCD bands which is about twice higher in the present work. ${ }^{3}$ The lower intensity of the VCD bands in the previous study is essentially due to the lower spectral resolution (i.e. $8 \mathrm{~cm}^{-1}$ vs. $4 \mathrm{~cm}^{-1}$ in our study).

It is noteworthy that the intensity of the VCD bands is very high with values rarely reached in molecular chirality. Enhancement of VCD has already been observed, to a lesser extent, in chelating chiral ligands coordinated to transition metals, and rationalized in part by invoking vibronic coupling with low-lying excited electronic states (LLES). ${ }^{20-24}$ This amplified VCD has also been used to elucidate the local chiral structure in biological macromolecules ${ }^{25-27}$ and quickly determine the handedness ${ }^{28}$ and enantiomeric excess of amino acids. ${ }^{29}$
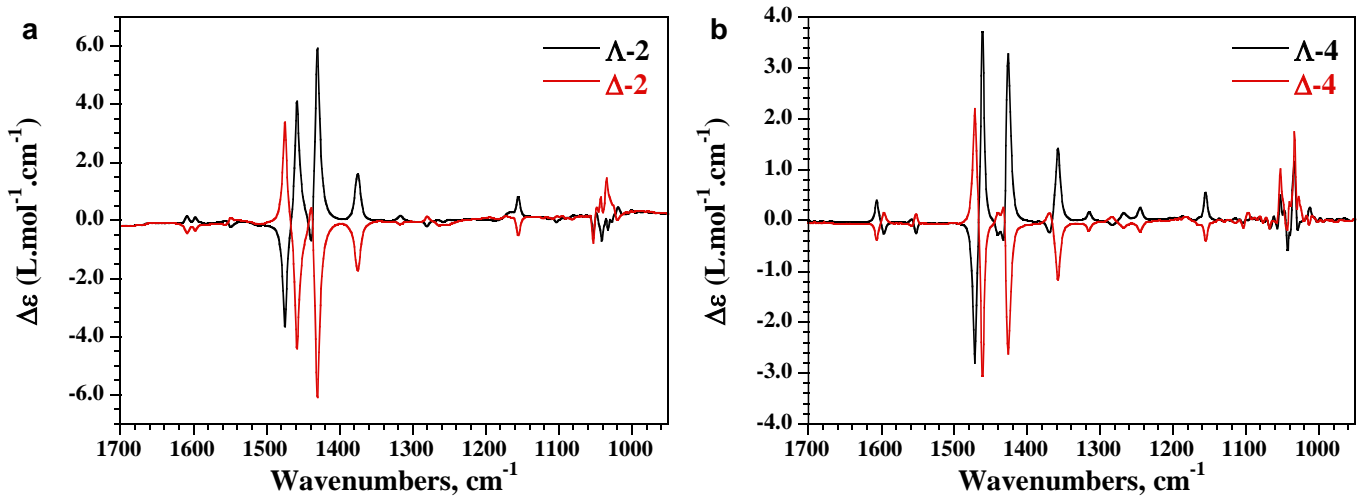

FIGURE 6 VCD spectra of a) 2 and b) 4 in $\mathrm{CD}_{3} \mathrm{CN}$. 

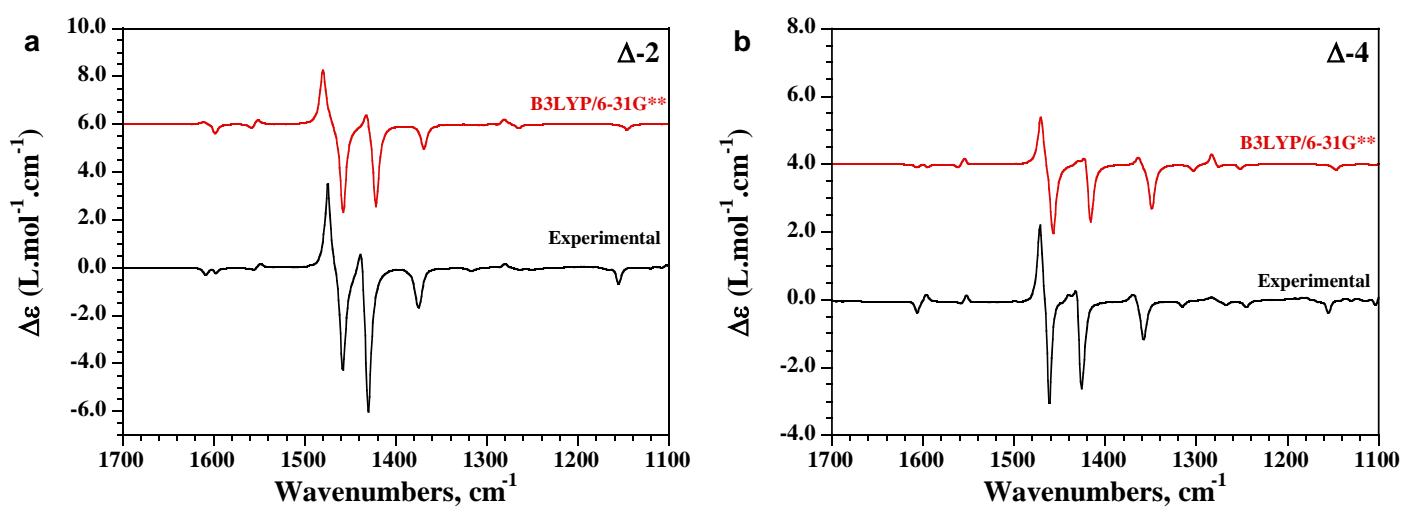

FIGURE 7 Comparison of experimental and calculated VCD spectra of a) $\Delta-\mathbf{2}$ and b) $\Delta-\mathbf{4}$.

Among the largest anisotropy factors observed is that corresponding to the stretching of $\mathrm{CN}^{-}$ligated to the Fe(III) ion in haemoglobin with a $g$ value (or vibrational dissymmetry factor) of $+2.4 \times 10^{-3} .30$

VCD enhancement by vibronic coupling has been shown to be dependent on the nature of the metal center. For example, Nafie et al. reported that the signs and the intensities of most of the VCD bands were very different in the VCD-enhanced (-)-sparteine complexes of cobalt(II) and nickel(II). ${ }^{20}$ Similar observations were made by Sato et al. when comparing the C-O bands in M(III) acac complexes. ${ }^{22}$ Comparing the cobalt and nickel complexes in the present system, most of the pyridyl modes exhibit the same sign for a given enantiomer $\left(\Delta\right.$, for example), except for the two components of the $v_{8 b}$ mode around $1600 \mathrm{~cm}^{-1}$, which have the same negative sign for the Co complex and a $(-,+)$ couplet for the Ni complex. Another small spectral difference is noted for the $\mathrm{C}-\mathrm{N}-\mathrm{C}$ asymmetric stretching mode between 1300 and $1400 \mathrm{~cm}^{-1}$, since only a single negative band is observed for $\Delta-\mathbf{2}$ whereas a biased (+,-) couplet is observed for $\Delta-\mathbf{4}$. Nevertheless, the signs of the most intense VCD bands for each enantiomer are not modified by the nature of the metal (Co or Ni), suggesting that the strong response cannot be easily attributed to vibronic coupling with LLES. This interpretation is supported by the fact that, unlike in previous studies, ${ }^{20,21}$ no electronic CD is detected in the VCD spectrum up to $4000 \mathrm{~cm}^{-1}$.

The VCD spectra of the $\Delta$ enantiomer of the $\left[\mathrm{M}_{3}(\mathrm{dpa})_{4} \mathrm{Cl}_{2}\right]$ model complexes were calculated using DFT (Figure 7), from optimized structures. The calculated spectra reproduce very well the sign and relative intensity of most of the bands observed in the experimental VCD spectra of the two complexes, although the overall intensity of the VCD spectra is underestimated in the calculations. The excellent agreement between experiment and theory is noteworthy, as it has been shown that DFT does not well simulate spectra that are enhanced due to coupling to LLES, ${ }^{21,23}$ and that consistency is highest when there is no evidence of VCD enhancement. ${ }^{31}$ In previous studies, the lack of agreement between theory and experiment is mainly reserved for bands where the symmetry of the LLES is the same as that for the vibrational displacement, thus providing a mechanism for vibronic coupling. ${ }^{23}$ In the present complexes, the large majority of VCD bands can be classified by symmetry such that the positive bands are associated with transitions corresponding to changes in electric dipole moment parallel with the M-M-M axis, while the negative bands consist of doubly degenerate modes with displacements perpendicular to the M-M-M axis. As the signs and the relative intensities of all of the main peaks, regardless of symmetry, are well reproduced by these ground-state calculations, it is another piece of evidence that suggests that any VCD enhancement of these peaks is not due to vibronic coupling of LLES.

The DFT calculations also reproduce remarkably well the experimental results expressed as vibrational dissymmetry factors (VDF or $g$ values, Figure 8). The calculations replicate not only the high experimental VDF values (on the order of $10^{-3}$ ), but also the higher intensity (ca. 2x) observed for the $\mathrm{Co}$ (II) complex compared to the $\mathrm{Ni}(\mathrm{II})$ compound. The reason for the higher intensity for the Co(II) compound is currently unclear. It should be mentioned that vibrationally induced ring currents generated in the ligands and enhanced by unpaired metal-based electrons have been offered as another mechanism for VCD enhancement. ${ }^{31}$ Considerable theoretical work has been previously undertaken on the model compounds $\left[\mathrm{M}_{3}(\mathrm{dpa})_{4} \mathrm{Cl}_{2}\right]$. In the cobalt derivative, the presence of metal-metal bonding gives rise to an electronic structure with metal-based frontier molecular orbitals, with little admixture of ligand-based orbitals. ${ }^{32}$ The ground state electronic structure implies a three-centered three-electron bond by way of the population of orbitals of $\sigma$, $\pi$, and $\delta$ symmetry, with one unpaired electron delocalized over the terminal metal centers in a $\sigma$ non-bonding orbital. ${ }^{32}$ Thus, the magnetic orbital is orthogonal to the
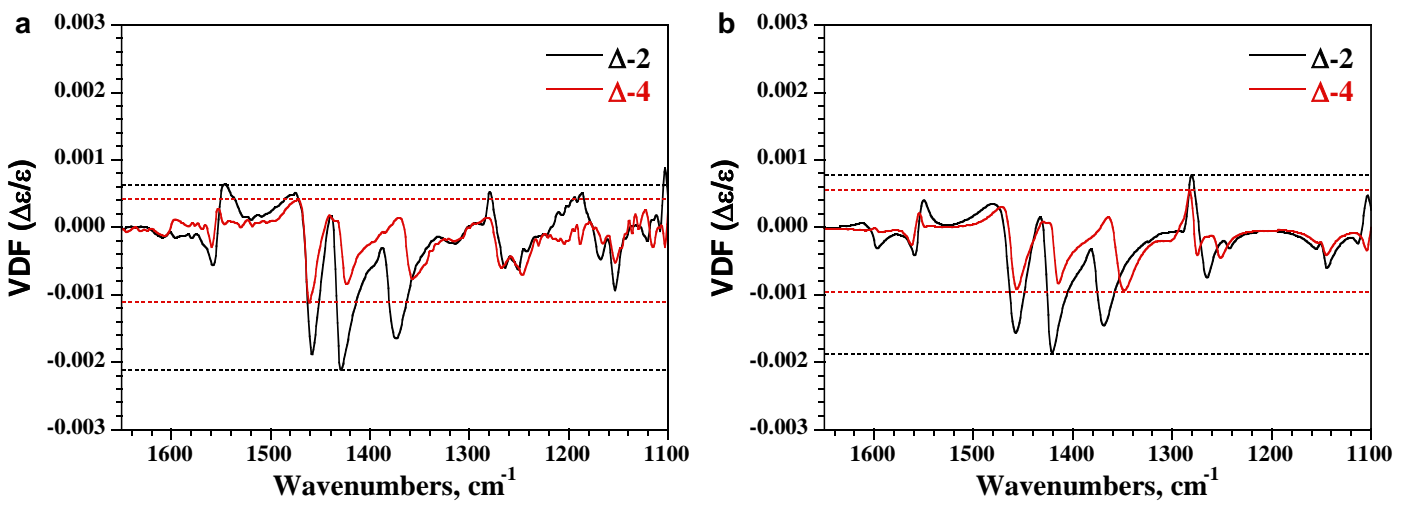

FIGURE 8 Comparison of a) experimental VDF values for $\Delta-\mathbf{2}$ and $\Delta-\mathbf{4}$ and b) comparison of theoretical VDF values for $\Delta-\mathbf{2}$ and $\Delta-\mathbf{4}$. 
ligand-metal orbitals. In the trinickel complex, metal-metal bonding is absent, and the spin density resides on the two terminal HS $S=1$ $\mathrm{Ni}(\mathrm{II})$ ions. ${ }^{33}$ In this "localized electron" picture, the magnetic orbitals would be considered to overlap with the ligand orbitals, contrary to the Co(II) complex for which there is little contribution of the ligand-based orbitals to the magnetic orbitals. Therefore, we would expect certain bands arising from $\mathrm{Ni}(\mathrm{II})$ compound to be modified if a ring current mechanism is operative. This is not is what is observed, instead the $\mathrm{Ni}(\mathrm{II})$ spectrum is globally less intense than the $\mathrm{Co}(\mathrm{II})$ one. Therefore, the influence of the magnetic orbitals is not obvious and other factors, such as the presence of metal-metal bonds in the cobalt complex may play a role.

\section{Conclusion}

Following our work on the analogous cobalt(II) system, we have shown that the use of the chiral anion $\left[\mathrm{As}_{2}(\operatorname{tartrate})_{2}\right]^{2-}$ is likewise effective in the resolution of trinickel paddlewheel complexes. These enantiomers crystallize in the non-centrosymmetric space group $P 42{ }_{1} 2$ and are isomorphous with the previously-reported cobalt analogue. The complexes are stable against racemization in solution, and can be conveniently studied by chiroptical spectroscopic methods. To simplify the VCD spectra, the $\left(\mathrm{NBu}_{4}\right)_{2}\left[\mathrm{M}_{3}(\mathrm{dpa})_{4}\left(\mathrm{CH} \mathrm{H}_{3} \mathrm{CN}\right)_{2}\right](\mathrm{AsT})_{2}$ salts were converted to the $\left[\mathrm{M}_{3}(\mathrm{dpa})_{4}\left(\mathrm{CH}_{3} \mathrm{CN}\right)_{2}\right]\left(\mathrm{PF}_{6}\right)_{2}$ salts, with retention of the original chirality. The VCD spectra of the cobalt and nickel complexes demonstrate a significant response, which does not change substantially according to the identity of the metal center. Theoretical calculations well reproduce the main bands for both compounds. The similar shape of the VCD spectra for the two compounds, their agreement with DFT calculated spectra, as well as the lack of any electronic CD in the IR spectral range, suggest that the high VDF values observed for the two complexes cannot be attributed to the vibronic coupling to LLES that is often observed in chiral transition metal complexes. In general, the strong chiroptical response of these compounds is likely due less to electronic reasons than to structural ones. These molecules are highly rigid, such that the spectra could be effectively modelled using only one conformation. Due to this rigid helicoidal structure, the intensity of the VCD bands are not diminished by contributions from different conformations.

\section{Acknowledgements}

This work was supported by the CNRS, the University of Bordeaux (PhD fellowship for AVP), the Conseil Régional de la Nouvelle Aquitaine, the European Union's Horizon 2020 research and innovation program under the Marie Sklodowska-Curie grant agreement No 706556 CHIMMM (Postdoctoral fellowship for MC). Computational facilities were provided by the MCIA (Mesocentre de Calcul Intensif Aquitain) of the University of Bordeaux and financed by the Conseil Régional de la Nouvelle Aquitaine. The authors thank S. Exiga for technical assistance and R. Clérac and J. Autschbach for useful discussions.

\section{Supporting information}

Additional supporting information may be found in the online version of this article at the publisher's website.

\section{REFERENCES AND NOTES}

1. Berry JF. Extended Metal Atom Chains. In: Cotton FA, Murillo CA, Walton RA, editors. Multiple Bonds between Metal Atoms, 3rd. ed. Springer US; 2005. p 669-706.

2. Clérac R, Cotton FA, Dunbar KR, Lu T, Murillo CA, Wang X. New Linear Tricobalt Complex of Di(2-pyridyl)amide (dpa), $\left[\mathrm{Co}_{3}(\mathrm{dpa})_{4}\left(\mathrm{CH}_{3} \mathrm{CN}\right)_{2}\right]\left[\mathrm{PF}_{6}\right]_{2}$. Inorg. Chem. 2000; 39: 3065-3070.

3. Armstrong DW, Cotton FA, Petrovic AG, Polavarapu PL, Warnke MM. Resolution of Enantiomers in Solution and Determination of the Chirality of Extended Metal Atom Chains. Inorg. Chem. 2007; 46: 1535-1537.

4. Warnke MM, Cotton FA, Armstrong DW. Enantioseparation of extended metal atom chain complexes: Unique compounds of extraordinarily high specific rotation. Chirality 2007; 19: 179-183.

5. Marcovich D, Tapscott RE. Carbon-13 NMR studies on arsenic(III) and antimony(III) dihydroxydicarboxylate complexes. J. Am. Chem. Soc. 1980; 102: 5712-5717.

6. Srinivasan A, Cortijo M, Bulicanu V, Naim A, Clérac R, Sainctavit P, Rogalev A, Wilhelm F, Rosa P, Hillard EA. Enantiomeric resolution and X-ray optical activity

of a tricobalt extended metal atom chain. Chem. Sci. 2018; 9: 1136-1143.

7. Valentín-Perez Á, Naim A, Hillard EA, Rosa P, Cortijo M. Enantiopure Chiral Coordination Polymers Based on Polynuclear Paddlewheel Helices and Arsenyl Tartrate. Polymers 2018; 10: 311.

8. Naim A, Bouhadja Y, Cortijo M, Duverger-Nedellec E, Flack HD, Freysz E, Guionneau P, lazzolino A, Hamouda AO, Rosa P, Stefanczyk O, Valentín-Perez A, Zeggar M. Design and Study of Structural Linear and Nonlinear Optical Properties of Chiral [Fe(phen) $\left.{ }_{3}\right]^{2+}$ Complexes. Inorg. Chem. 2018; 57: 14501-14512.

9. Berry JF, Cotton FA, Daniels LM, Murillo CA, Wang X. Oxidation of $\mathrm{Ni}_{3}(\mathrm{dpa})_{4} \mathrm{Cl}_{2}$ and $\mathrm{Cu}_{3}(\mathrm{dpa})_{4} \mathrm{Cl}_{2}$ : Nickel-Nickel Bonding Interaction, but No Copper-Copper Bonds. Inorg. Chem. 2003; 42: 2418-2427.

10. Bruker (2012). APEX2, SADABS, and SAINT. Bruker AXS Inc., Madison, Wisconsin, USA. 
11. Sheldrick GM. A short history of SHELX. Acta Cryst. 2008; A64: 112-122.

12. Sheldrick GM. Crystal structure refinement with SHELXL. Acta Cryst. 2015; A71: 3-8.

13. Dolomanov OV, Bourhis LJ, Gildea RJ, Howard JAK, Puschmann H. OLEX2: A complete structure solution, refinement and analysis program. J. Appl. Cryst. 2009; 42: 339-341.

14. Buffeteau T, Lagugné-Labarthet F, Sourisseau C. Vibrational Circular Dichroism in General Anisotropic Thin Solid Films: Measurement and Theoretical Approach. Appl. Spectrosc. 2005; 59: 732-745.

15. Frisch MJ, Trucks GW, Schlegel HB, Scuseria GE, Robb MA, Cheeseman JR, Scalmani G, Barone V, Petersson GA, Nakatsuji H, Li X, Caricato M, Marenich AV, Bloino J, Janesko BG, Gomperts R, Mennucci B, Hratchian HP. Gaussian 16, Revision B.01, 2016.

16. Berry JF, Cotton FA, Lu T, Murillo CA, Wang X. Enhancing the Stability of Trinickel Molecular Wires and Switches: $\mathrm{Ni}_{3}{ }^{6+} / \mathrm{Ni}_{3}{ }^{7+}$. Inorg. Chem. 2003; 42: 3595-3601.

17. Hsiao CJ, Lai SH, Chen IC, Wang WZ, Peng SM. Metal-Metal Bonding and Structures of Metal String Complexes $\mathrm{Cr}_{3}(\mathrm{dpa})_{4} \mathrm{Cl}_{2}$, $\mathrm{Cr}_{3}(\mathrm{dpa})_{4}(\mathrm{NCS})_{2}$, and $\left[\mathrm{Cr}_{3}(\mathrm{dpa})_{4} \mathrm{Cl}_{2}\right]\left(\mathrm{PF}_{6}\right)$ from IR, Raman, and Surface-Enhanced Raman Spectra. J. Phys. Chem. A 2008; 112: 1352813534.

18. Lai SH, Hsiao CJ, Ling JW, Wang WZ, Peng SM, Chen IC. Metal-metal bonding in metal-string complexes $M_{3}(d p a){ }_{4} X_{2}(M=N i$, Co, $\mathrm{dpa}=\mathrm{di}(2$-pyridyl)amido, and $\mathrm{X}=\mathrm{Cl}$, NCS) from resonance Raman and infrared spectroscopy. Chem. Phys. Lett. 2008; 456: $181-185$.

19. Clérac R, Cotton FA, Daniels LM, Dunbar KR, Kirschbaum K, Murillo CA, Pinkerton AA, Schultz AJ, Wang X. Linear Tricobalt Compounds with $\mathrm{Di}(2$-pyridyl)amide (dpa) Ligands: Temperature Dependence of the Structural and Magnetic Properties of Symmetrical and Unsymmetrical Forms of $\mathrm{Co}_{3}(\mathrm{dpa})_{4} \mathrm{Cl}_{2}$ in the Solid State. J. Am. Chem. Soc. 2000; 122: 6226-6236.

20. He Y, Cao X, Nafie LA, Freedman TB. Ab Initio VCD Calculation of a Transition-Metal Containing Molecule and a New Intensity Enhancement Mechanism for VCD. J. Am. Chem. Soc. 2001; 123: 11320-11321.

21. Johannessen C, Thulstrup PW. Vibrational circular dichroism spectroscopy of a spin-triplet bis-(biuretato) cobaltate(iii) coordination compound with low-lying electronic transitions. Dalton Trans. 2007; 10: 1028-1033.

22. H. Sato, T. Taniguchi, A. Nakahashi, K. Monde, A. Yamagishi. Effects of Central Metal lons on Vibrational Circular Dichroism Spectra of Tris-(ß-diketonato)metal(III) Complexes. Inorg. Chem. 2007; 46: 6755-6766.

23. Pescitelli G, Lüdeke S, Górecki M, Di Bari L. Symmetry-Dependent Vibrational Circular Dichroism Enhancement in Co(II) Salicylaldiminato Complexes, J. Phys. Chem. Lett. 2019; 10: 650-654.

24. Nafie LA. Theory of Vibrational Circular Dichroism and Infrared Absorption: Extension to Molecules with Low-Lying Excited Electronic States. J. Phys. Chem. A 2004; 108: 7222-7231.

25. Domingos SR, Hartl F, Buma WJ, Woutersen S. Switchable Amplification of Vibrational Circular Dichroism as a Probe of Local Chiral Structure. ChemPhysChem 2015; 16: 3363-3373.

26. Domingos SR, Huerta-Viga A, Baji L, Amirjalayer S, Dunnebier DAE, Walters AJC, Finger M, Nafie LA, de Bruin B, Buma WJ, Woutersen S. Amplified Vibrational Circular Dichroism as a Probe of Local Biomolecular Structure. J. Am. Chem. Soc. 2014; 136: 35303535.

27. Domingos SR, Sanders HS, Hartl F, Buma WJ, Woutersen S. Switchable Amplification of Vibrational Circular Dichroism as a Probe of Local Chiral Structure. Angew. Chem. Int. Ed. 2014; 53: 14042-14045.

28. Berardozzi R, Badetti E, Carmo dos Santos NA, Wurst K, Licini G, Pescitelli G, Zonta C, Di Bari L. Co(II)-induced giant vibrational CD provides a new design of methods for rapid and sensitive chirality recognition. Chem. Commun. 2016; 52: 8428-8431.

29. Arrico L, Angelici G, Di Bari L. Taking Advantage of Co(II) Induced Enhanced VCD for the Fast and Sensitive Determination of Enantiomeric Excess. Org. Biomol. Chem. 2017; 15: 9800-9803.

30. Bormett RW, Smith GD, Asher SA, Barrick D, Kurtz Jr. DM. Vibrational Circular Dichroism Measurements of Ligand Vibrations in Haem and Non-haem Metalloenzymes. Faraday Discuss. 1994; 99: 327-339.

31. Merten C, Hiller K, Xu Y. Effects of electron configuration and coordination number on the vibrational circular dichroism spectra of metal complexes of trans-1,2-diaminocyclohexane. Phys. Chem. Chem. Phys. 2012; 14: 12884-12891.

32. Rohmer MM, Strich A, Bénard M, Malrieu JP. Metal-Metal Bond Length Variability in $\mathrm{Co}_{3}$ (dipyridylamide) ${ }_{4} \mathrm{Cl}_{2}$ : Bond-Stretch Isomerism, Crystal Field Effects, or Spin Transition Process? A DFT Study. J. Am. Chem. Soc. 2001; 123: 9126-9134.

33. Kiehl P, Rohmer MM, Bénard M. Electron Delocalization in Nickel Metallic Wires: A DFT Investigation of $\mathrm{Ni}_{3}(\mathrm{dpa})_{4} \mathrm{Cl}_{2}$ and $\left[\mathrm{Ni}_{3}(\mathrm{dpa})_{4}\right]^{3+}$ $(\mathrm{dpa}=$ Dipyridylamide) and Extension to Higher Nuclearity Chains. Inorg. Chem. 2004; 43: 3151-3158. 